\title{
Editorial - Volume 5, Number 1
}

Citation: Cannon, R. L. (2018). Editorial - Volume 5, Number 1. NeuroRegulation, 5(1), 2. http://dx.doi.org/10.15540/nr.5.1.2

Copyright: (c) 2018. Cannon. This is an Open Access article distributed under the terms of the Creative Commons Attribution License (CC-BY).
*Address correspondence to: Rex L. Cannon, PhD, BCN, Knoxville Neurofeedback Group, 7147 Kingston Pike, Ste 103, Knoxville, TN 37919, USA. Email: rcannonphd@gmail.com
Welcome to NeuroRegulation Volume 5, Issue 1; more so, welcome to our fifth year. We are excited to reach this goal and will continue to seek out further opportunities to advance the fields of neurofeedback, biofeedback, and applied neuroscience. It is important for the public to know about these methods of performance enhancement and therapeutic intervention. Neurofeedback is not a new technology. In fact, it has been in application for over 60 years. Technology has afforded great advancements in the methods and delivery; however, operant conditioning of the EEG is a veteran in terms of psychological interventions and should not be characterized as anything less. There is a large data demonstrating the effects across clinical symptoms as well as normative groups. Our goal is to provide sound learning principles in order to facilitate improvements in self-regulation and performance and reduce psychological distress and symptoms.

In the current issue Erik Peper and Richard Harvey discuss the implications of digital addiction and associated symptoms. In the age of technology and constant exposure to digital content, this is a timely topic given few recommendations have been given to define a healthy range of exposure and potential difficulties that may arise from overexposure. Matthew Goodman, Nicolette Castro, Mary Sloan, Rita Sharma, Michael Widdowson, Eduardo Herrera, and Jaime Pineda provide data concerning a neurovisceral approach to autism and aiding individuals in targeting self-regulation and core symptoms using a multimodal approach as well as a potential approach to aid symptom improvement in individuals with autism spectrum disorders. The authors utilize a variety of novel techniques and report interesting findings. Vera Grin-Yatsenko, Siegfried Othmer, Valery Ponomarev, Sergey Evdokimov, Yuri Konoplev, and Juri Kropotov provide case studies of infra-low neurofeedback effects in depression. There is a need for more case studies of this method in order to educate professionals and the general public on the variety of methods used to address the neural mechanisms associated with specific syndromes. Finally, Heidi Hillman and Charles Chapman provide a review of biofeedback as a method to intervene and improve difficulties with anger management. This article is informative and provides examples of published data to aid clients with difficulties managing affective processes, with an emphasis on anger.

NeuroRegulation thanks these authors for their valuable contributions to the scientific literature for neurofeedback and learning. We strive for high quality and interesting empirical topics. We encourage the members of ISNR and other biofeedback and neuroscience disciplines to consider publishing with us. It is important to stress that publication of case reports is always useful in furthering the advancement of an intervention for both clinical and normative functioning. We encourage researchers, clinicians, and students practicing neurofeedback to submit case studies! Thank you for reading NeuroRegulation!

Rex L. Cannon, PhD, BCN

Editor-in-Chief

Email: rcannonphd@gmail.com

Published: March 31, 2018 